American Journal of Agricultural and Biological Sciences 6 (3): 429-432, 2011

ISSN 1557-4989

C 2011 Science Publications

\title{
The Body Calming and Body Vitalizing Effects of Vernonia Amygdalina Leaf Extract and Leaf Powder and their Mechanisms
}

\author{
Utoh-Nedosa Uchechukwu Anastasia \\ Department of Pharmacology and Toxicology, Faculty of Pharmaceutical Sciences, \\ Nnamdi Azikiwe University, P.M.B. 5025, Awka, Anambra State, Nigeria
}

\begin{abstract}
Problem statement: Vernonia amygdalina (V. amygdalina) leaf soup is regarded by the indigenous Igbo people of South Eastern Nigeria as their best leafy vegetable soup. Despite the bitterness of the bitter leaf soup, the native eaters of the soup feel very content when they eat pounded carbohydrate foods with it. Oral $V$. amygdalina leaf extract was taken methodically in this study to examine the generalized effect of oral $V$. amygdalina leaf intake on the human body. Approach: Vernonia amygdalina leaf extract and leaf powder produced a generalized calming effect on the whole body of the extract-treated human subject. The relaxation effect of leaf extract of V. amygdalina on the skeletal, smooth and cardiac muscles of the subject made the whole body of the subject to function at close to basal metabolic rate, in an efficient, calm and alert manner. Results: V. amygdalina leaf extract produced its calming effects on the body by its action as an inhibitory first messenger that inhibited $\mathrm{x}_{2}$-adrenoceptors of the whole body of the subject by occupation of $\beta_{3}$-adreceptors on membranes the body's cells. Such inhibitory action on $\alpha_{2}$ adrenoceptors of the body (especially of adipose tissues; smooth, cardiac and skeletal muscles and of tissues of the body involved with control of excess blood sugar) caused the inhibition of the accumulation of cyclic AMP and resulted in a generalized calming effect on the body. $V$. amygdalina extract acted inhibited $\alpha_{2}$-adrenoceptors of the body by acting as an inhibitory G-protein on $\beta_{3}$ adrenoceptores of the cells of the whole body. Conclusion: This study concludes that the mechanism by which $V$. amygdalina leaf active principles exert a calming effect on the whole human body is by acting as an inhibitory first messenger that sits on the membrane receptors of body tissues to activate an inhibitory G-protein adenylyl cyclase messenger which causes an inhibition of the accumulation of cyclic AMP at the sites where cyclic AMP accumulation would have resulted in excitatory action. By this inhibitory action $V$. amygdalina antagonized explosive energy utilization in the various tissues of the body thereby causing a generalized calming of the body.
\end{abstract}

Key words: $\beta_{3}$-adreceptors, vernonia amygdalina, metabolic rate, G-protein, leaf soup, calming effects, lipolytic action

\section{INTRODUCTION}

Vernonia amygdalina leaf extract has been found to be effective in the antimicrobial infections (including malaria) and to exhibit anti-oxidant/liver protective effects. Antimicrobial infections, malaria and oxidative stress are accompanied by pyrexia and body function derangement. This study investigated the effects of Vernonia amygdalina leaf extract on the body calming and body vitality

\section{MATERIALS AND METHODS}

An Infusion of fragments of dried wholesome mature red stalked $V$. amygdalina (bitter leaf) leaves was made by putting them in twice their own volume of boiling drinking water in a clean cooking pot. Stirring of the leaf fragments for 10-15 minutes enhanced complete effusion of the $V$. amygdalina leaf extract into the boiling water.

Red stalked spindle shaped Vernonia amygdalina leaves which were dried in low sunshine and ground into very fine powder with a grinding mill. Ingestion of the $V$. amygdalina powder with the finely ground fibers mimicked the eating of the bitter leaf soup 9liquid) and the bitter leaf fibers together in the bitter leaf soup.

$V$. amygdalina leaf extract treatment: The treatment consisted of the oral intake of the $V$. amygdalina leaf extract for one month and the observation of stipulated eating behavior by the human subject. 
The subject took $70 \mathrm{ml}$ of the $V$. amygdalina leaf infusion orally 4 times daily; for one month while observing the following listed dietary restrictions.

Treatment with the $\boldsymbol{v}$. amygdalina leaf powder: The $V$. amygdalina leaf powder treatment was taken as a separate treatment from the $V$. amygdalina leaf extract treatment. This treatment consisted of ingesting 10 grams of the $v$. amygdalina powder four times daily for one month while observing the dietary restrictions.

Dietary restrictions: The subject abstained from the following foods: lard; vegetable oil; butter/margarine; mayonnaise; grated coconut; bacon; ground nut/peanut butter; nuts like palm nut, coconut, date palm; oil fried foods; oily seeds like beniseed, mellon seed, sun flower seed; oily fruits like avocado pea, Nigerian pea ; oily soups, stews or gravies; oily cooked or prepared meals like salads, bean cakes and from pastries or flour foods like dough nuts, burns, cakes, spaghetti/macaroni, bread; alcohol or alcoholic drinks; beverages like tea , coffee, cocoa beverages; soft drinks (including malt drinks and carbonated drinks); tobacco or tobacco products; garlic and acidic food spices and condiments; artificial food seasoning (artificial salt or salt substitutes including potash).

Permitted diet and eating behavior: The subject's meals consisted of two daily meals which contained their normal daily requirements of proteins, non-acidic fruits; mineral salts and water. Only one third of the carbohydrates meals and one tenth of the fats and oils previously consumed by the researcher was eaten by the subject. Two thirds of the carbohydrates which the subject previously consumed were replaced by leafy green vegetables.

\section{RESULTS}

The same results were obtained from the one month treatment with the $V$. amygdalina leaf extract or its leaf powder. These results are shown in the photographs shown in Fig. 2-4.

A comparism of the external features of the body in Fig. 1 with those of Fig. 2-4 shows that the $V$. amygdalina leaf extract treatment produced a generalized calming effect on the subject's body. The subject also reported that she felt calm and relaxed and that her body was functioning in a more relaxed state or at a lower energy level than before the $V$. amygdalina treatment.

The treated subject reported that her body felt more calm, more relaxed, invigorated and that she felt more contented than before the taking of the $V$. amygdalina leaf extract or powder.
Other side effects of the $V$. amygdalina extract treatment included the loss $f$ excess body fat, The subject also reported being full of new strength and zest and having lost excess body fat, the presence of a smoother healthier skin and a skin that was tighter on the muscles of the flesh and of a lighter shinier colour. The skin, anti-diabetic and anti-obesity effects of $V$. amygdalina leaf extract have been demonstrated in our other studies (Lisheng et al., 1991; Muthuraman et al., 2009; Nakaya et al., 1988; Pang et al., 1988; Pinero Estrada et al., 2001; Shih et al., 2003; Suda et al., 1986; Bhatt et al., 2009).

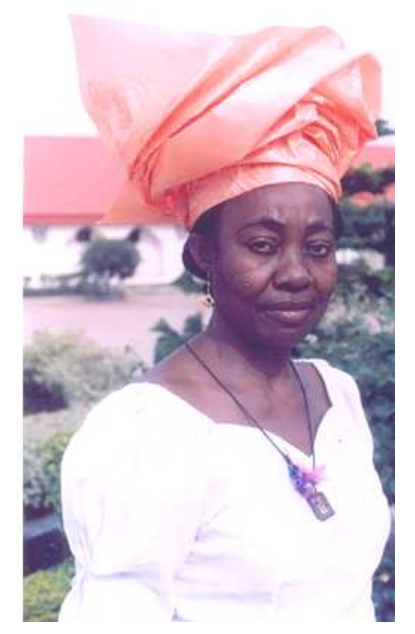

Fig. 1: Shows the subject before the V. amygdalina leaf extract treatment while

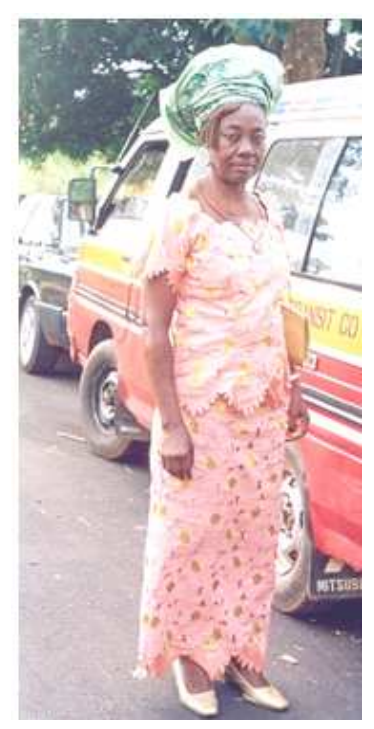

Fig. 2: Show the effect of the $V$. amygdalina extract treatment on body calming and body vitality 
Am. J. Agri. \& Biol. Sci., 6 (3): 429-432, 2011

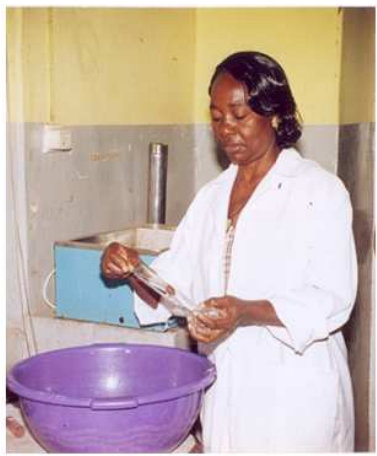

Fig. 3: Show the effect of the $V$. amygdalina extract treatment on body calming and body vitality

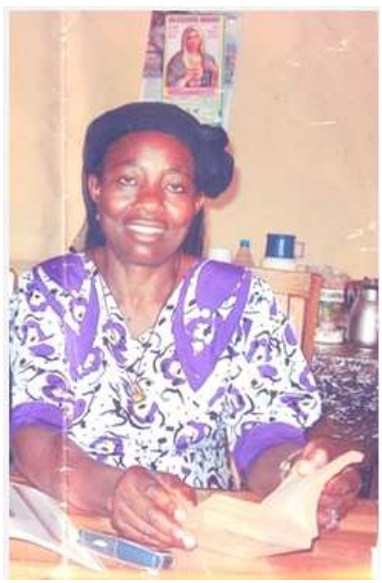

Fig. 4: Show the effect of the V. amygdalina extract treatment on body calming and body vitality

\section{DISCUSSION}

The calming effects of $V$. amygdalina leaf extract and leaf powder on the subject's body and outlook are suggested to be produced by the relaxation effects of the extract on the skeletal, cardiac and smooth muscles all over the body. The energy-moderation effects of $V$. amygdalina extract on the cardiac, smooth and skeletal muscles that control the activities of the human body resulted in smooth low energy- functioning of all the organs of the body. This action of $V$. amygdalina extract was responsible for its calming effects on the muscular activities of the subject's body. The effects of $V$. amygdalina leaf extract on the muscles of the body were augmented by the excess fat elimination and the anti-obesity effects of the extract.

Effect of Increase in the oxygen carrying power of the blood: $V$. amygdalina leaf extract caused increases in the red blood cell population of extract-treated subjects (unpublished findings). This effect was demonstrated in our studies with dihydroartemisinin. This elevation effect of $V$. amygdalina leaf extract on the blood increased the oxygen- carrying power of the blood in the subject of this study. Thus the muscles of the body under the effect of $V$. amygdalina extract work with greater efficiency as the oxygen- carrying power of their blood supply to various organs was increased.

The antioxidant (Mucimapura et al., 2010; Balasubramanyam et al., 2006; Akbari-Asbagh et al., 2010; Al-Attar, 2010a; 2010b) effects of V. amygdalina extract account for the energy-lowering effects of the extract that produced the calming of the body.

Part of the lowering of the energy demands of the body by $V$. amygdalina extract occurred by inhibitory lipolytic action of the extract in adipose tissues.

These lipolytic and excess fat elimination properties of $V$. amygdalina are carried out by $\mathrm{x}_{2}$ receptor inhibition resulting in inhibition of the accumulation of cyclic AMP. This lipolytic and excess fat elimination effect of $V$. amygdalina thus disallows the huge energy yields which would otherwise have accrued to the body by normal B-oxidation of fats in the body. This antagonism of the energy yield from fat metabolism is largely responsible for the calming effect of $V$. amygdalina extract on all the tissues of the body including the brain.

A similar $\beta$-oxidation stimulation effect of $V$. amygdalina occurs in the mitochondria of cardiac, smooth and skeletal muscle cells of the whole body to antagonize their energy generation process. This action accounts for the calming of the muscular activities of the body. The generalized calming of the body by $V$. amygdalina leaf extract (and by implication bitter leaf soup) was produced by a combination of the excess body fat lipolytic/elimination effects of the extract; its hypoglycaemic effects and its inhibitory energy generation antagonism effects on all muscles of the body. Soursop plant extracts employ similar energy generation antagonism actions to execute their medicinal effects.

$V$. amygdalina leaf extract produced its calming effects on the body by its action as an inhibitory first messenger that inhibited $\mathrm{x}_{2}$-adrenoceptors by occupation of $\beta_{3}$-adreceptors on membranes of adipose tissues, smooth, cardiac and skeletal muscles and other tissues of the body to cause the inhibition of the accumulation of cyclic AMP. $V$. amygdalina extract acted on the above mentioned $\beta_{3}$ adrenoceptores I as an inhibitory $\mathrm{G}_{1}$ protein to bring about the body calming effect on the body. 


\section{CONCLUSION}

The energy generation inhibition effects of $V$. amygdalina leaf extract on the muscles of the body; on excess body fat and on excess blood sugar coupled to the increased oxygen carrying power of the blood produced by the effect of the extract on the blood (unpublished findings) made the body to work at low energy and with increased efficiency (at reduced $\mathrm{V}_{02}$ $\max$ ) to account for the increased vigor (despite the body calming effect of the extract) experienced by the subject.

\section{REFERENCES}

Akbari-Asbagh, F., E. Mostafavi, K. Hamdi, O. Azmodeh and A. Ghasemynejad et al., 2010. Relation of serum and semen malondialdehyde and total anti-oxidants with sperm parameters in infertile men. Am. J. Immunol., 6: 43-49. DOI: 10.3844/ajisp.2010.43.49

Al-Attar, A.M., 2010a. Physiological study on the effect of Acalypha wilkesiana leaves extract on streptozotocin-induced experimental diabetes in male mice. Am. Med. J., 1: 51-58. DOI: 10.3844/amjsp.2010.51.58

Al-Attar, A.M., 2010b. Antilithiatic influence of spirulina on ethylene glycol-induced nephrolithiasis in male rats. Am. J. Biochem. Biotechnol., 6: 25-31. DOI: 10.3844/ajbbsp.2010.25.31

Balasubramanyam, A., R.V. Sekhar, F. Jahoor, H.J. Pownall and D. Lewis, 2006. Pathophysiology of adipocyte defects and dyslipidemia in HIV lipodystrophy: New evidence from metabolic and molecular studies. Am. J. Infect. Dis., 2: 167-172. DOI: 10.3844/ajidsp.2006.167.172

Bhatt, N.M., S. Barua and S. Gupta, 2009. Protective effect of Enicostemma littorale blume on rat model of diabetic neuropathy. Am. J. Infect. Dis., 5: 99105. DOI: 10.3844/ajidsp.2009.99.105
Lisheng, L., G. Baojiang, R. Jihong, Q. Guangquan and W. Botang, 1991. Inhibitive effect and mechanism of polysaccharide of Spirulina platensis on transplanted tumor cells in mice. Marine Sci., 5: 33-38.

Mucimapura, S., J. Wattanathorn, S. Thongrong, K. Chaisiwamongkol and B. Sripanidkulchai, 2010. Morus alba enhanced functional recovery after sciatic nerve crush injury. Am. J. Agric. Biol. Sci., 5: 294-300. DOI: 10.3844/ajabssp.2010.294.300.

Muthuraman, P., R. Senthilkumar and K. Srikumar, 2009. Alterations in beta-islets of Langerhans in alloxan-induced diabetic rats by marine Spirulina platensis. J. Enz. Inhib. Med. Chem., 24: 1253-256. DOI: $10.3109 / 14756360902827240$

Nakaya, N., Y. Homma and Y. Goto, 1988. Cholesterol lowering effect of spirulina. Nutr. Rep. Int., 37: 1329-1337.

Pang, Q.S., B.J. Guo and J.H. Ruan, 1988. Enhancement of endonuclease activity and repair DNA synthesis by polysaccharide of Spirulina platensis. Yi Chuan Xue Bao., 15: 374-381. PMID: 2856229

Pinero Estrada, J.E., P. Bermejo Bescós and A.M. Villar del Fresno, 2001. Antioxidant activity of different fractions of Spirulina platensis protean extract. Farmaco, 56: 497-500. PMID: 11482785

Shih, S.R., K.N. Tsai, Y.S. Li, C.C. Chueh and E.C. Chan, 2003. Inhibition of enterovirus 71-induced apoptosis by allophycocyanin isolated from a bluegreen alga Spirulina platensis. J. Med. Virol., 70: 119-125. PMID: 12629652

Suda, D., J. Schwartz and G. Shklar, 1986. Inhibition of experimental oral carcinogenesis by topical beta carotene. Carcinogenesis, 7: 711-715. PMID: 3084114 